Original Article

\title{
FORMULATION AND EVALUATION OF COLON TARGETED MATRIX TABLET USING NATURAL TREE GUMS
}

\author{
POREDDY SRIKANTH REDDY, PENJURI SUBHASH CHANDRA BOSE, DAMINENI SARITHA, VUPPULA SRUTHI \\ Department of Pharmaceutics, MNR College of Pharmacy, Sangareddy, Telangana, ${ }^{1}$ Department of Pharmaceutics, Sultan-ul-Uloom College \\ of Pharmacy, Hyderabad, Telangana \\ Email: penjurisubhash@gmail.com
}

Received: 11 May 2018 Revised and Accepted: 14 Aug 2018

\section{ABSTRACT}

Objective: To develop a novel colon targeted tablet formulation using natural polysaccharides such as kondagogu gum and ghatti gum as carriers and diltiazem hydrochloride as a model drug.

Methods: The polymer-drug tablets were prepared by wet granulation technique, coated with two layers viz., inulin as an inner coat followed by shellac as outer coat and evaluated for properties such as average weight, hardness and coat thickness. In vitro release studies of prepared tablets were carried out for $2 \mathrm{~h}$ in $\mathrm{pH} 1.2 \mathrm{HCl}$ buffer, $3 \mathrm{~h}$ in $\mathrm{pH} 7.4$ phosphate buffer and $6 \mathrm{~h}$ in simulated colonic fluid (SCF) in order to mimic the conditions from mouth to colon.

Results: Percentage weight variation, percent friability and content of active ingredient for all the formulations were found to be well within United States Pharmacopoeia (USP) limits. Out of both the polymers, the tablets prepared with ghatti gum showed the maximum hardness of $7.1 \mathrm{~kg} / \mathrm{cm}^{2}$. The FTIR spectra of pure diltiazem $\mathrm{HCl}$ and the formulation KF3 were found to be identical. From the DSC, it was evident that the melting point peak of diltiazem $\mathrm{HCl}$ and formulation $\mathrm{KF} 3$ were observed at 217.16 and $218.34{ }^{\circ} \mathrm{C}$ respectively. In vitro studies revealed that the tablets coated with shellac $(2.5 \% \mathrm{w} / \mathrm{w})$, prevented the drug release in stomach environment and inulin coated tablets (4\% w/w) have limited the drug release in the small intestinal environment. The data obtained from in vitro drug release studies were fit into Peppas model and in all the cases the value of A was found to be more than 2, i.e., drug release by a combination of both diffusion and erosion-controlled drug release.

Conclusion: The study revealed that polysaccharides as carriers and inulin and shellac as a coating material can be used effectively for colon targeting of drugs for treating local as well as systemic disorders.

Keywords: Colon targeted drug delivery system, Diltiazem $\mathrm{HCl}$, Kondagogu gum, Ghatti gum, In vitro dissolution

(C) 2018 The Authors. Published by Innovare Academic Sciences Pvt Ltd. This is an open-access article under the CC BY license (http://creativecommons.org/licenses/by/4.0/) DOI: http://dx.doi.org/10.22159/ijpps.2018v10i9.27255

\section{INTRODUCTION}

Oral administration of drugs is one of the most convenient routes and is associated with superior patient compliance compared to other routes of drug administration [1]. Targeting drug to a specific area not only increases the therapeutic efficacy of drugs but also it aims to decrease the toxicity associated with drugs to allow lower doses to be used in therapy [2]. In recent studies, colon targeted drug delivery systems are gaining importance to treat local pathologies of the colon and also for the systemic delivery of protein and peptide drugs [3].

Drug targeting to the colon is also useful when a delay in drug absorption is desired from a therapeutic point of view, such as treatment of diseases that have peak symptoms in the early morning like nocturnal asthma, angina or arthritis [4, 5]. CODES ${ }^{\mathrm{TM}}$ is a unique technology that was developed by utilizing a unique mechanism involving lactulose, which acts as a trigger form site-specific drug release in the colon $[6,7]$. The system consists of a traditional tablet core containing lactulose, which is coated with and soluble acid material like Eudragit E $[8,9]$.

Kondagugu gum (KG) is the dried exudates obtained from tree Cochlospermum gossypium belonging to the family Bixaceae [10,11]. It is used as a wound dressing sponge [12], food additive [13], buccal disc [14], the carrier in preparing floating drug delivery system [15] and a polyelectrolyte complex in combination with chitosan [16]. Gum ghatti is a complex non-starch polysaccharide obtained as amorphous translucent mucilage from wounds in the bark of Anogeissus latifolia [17]. Ghatti gum has also been used for preparing matrix tablets for domperidone [18], a floating drug delivery system [19] and also as an emulsifying agent [20].
Inulin is a polysaccharide obtained from plants such as onion, garlic, chicory, artichoke, etc. Only enzymes secreted by the microflora of colon degrade inulin [21]. Shellac is a resinous secretion of the insect Laccifer lacca and it is used as an enteric coat to prevent the drug release from the tablet in the stomach [22]. The drug selected for the present study is diltiazem hydrochloride, a calcium channel blocker, which is used in the treatment of early morning angina [23]. The present work aims to develop a novel colon targeted tablet formulation using kondagogu gum and ghatti gum as carriers and diltiazem hydrochloride as a model drug.

\section{MATERIALS AND METHODS}

\section{Materials}

Diltiazem $\mathrm{HCl}$ was obtained as a gift sample from M/s Divis Laboratories, Hyderabad, India. Diltiazem $\mathrm{HCl}$ is a white, odorless, crystalline powder freely soluble in water and methanol. Kondagogu gum and ghatti gum were purchased from the Girijan Co-operative Society, Govt. of Andhra Pradesh, Hyderabad. Inulin and shellac were procured from M/s Loba Chemie, Mumbai, India. All other ingredients used were of analytical grade.

\section{Purification of gums}

First the extraneous foreign matter like bark etc was separated from both kondagogu gum and ghatti gum, and then powdered using a mixer grinder and passed through sieve \#80. The powdered gum was dispersed in distilled water to get a $1 \%$ solution, kept in a sonicator for 10 min until it was clear and then added to an equimolar mixture of acetone and ethanol $(2: 1 \mathrm{v} / \mathrm{v})$ to give precipitation of gum. The precipitated polymer was kept in an oven at $40{ }^{\circ} \mathrm{C}$ for drying, powdered and evaluated for general characteristic properties [18]. 


\section{Preparation of diltiazem HCl-polymer matrix tablets}

Preliminary studies had demonstrated that directly compressed kondagogu gum and ghatti gum formulations lacked the required mechanical strength. Hence all the core tablets were prepared by wet granulation technique. Accurately weighed quantities of the drug, polymer (kondagogu gum/ghatti gum) and binder (PVP K-30, 3\% w/w) were physically blended in a mortar and pestle. The required quantity of the ethanol (solvent) was added and the resultant mixture was mixed thoroughly to form a dough mass suitable for the preparation of granules. The dough mass was then passed through sieve \# 22 to form granules which were dried in an oven at $60{ }^{\circ} \mathrm{C}$. The granules were mixed with required quantities of lactose (diluent) and lubricant (magnesium stearate, $2 \% \mathrm{w} / \mathrm{w}$ ) and were compressed to form tablets in a 10-station rotary tablet machine (Rimek, Mumbai, India) at 10 RPM and using 9 $\mathrm{mm}$ round concave punches at optimum pressure [4, 15]. Three formulations of 300 tablets each were prepared with different amount of kondagogu gum viz., 25, 50 and $75 \% \mathrm{w} / \mathrm{w}$ of the tablet (KF1, KF2 and KF3) and ghatti gum-based matrix tablets (GF1, GF2 and GF3 code for 25,50 and $75 \% \mathrm{w} / \mathrm{w}$ of ghatti gum respectively) as shown in table 1 . The prepared core tablets were evaluated for tablet properties such as hardness, thickness, weight variation, percent friability and drug content. Drug content studies were carried out to evaluate the amount of drug present in the prepared tablet.

Table 1: Composition of diltiazem $\mathrm{HCl}$ colon targeted tablets

\begin{tabular}{|c|c|c|c|c|c|c|}
\hline \multirow[t]{2}{*}{ Ingredients } & \multicolumn{6}{|c|}{ Formulation code and weight in $\mathrm{mg}$} \\
\hline & KF1 & KF2 & KF3 & GF1 & GF2 & GF3 \\
\hline Diltiazem $\mathrm{HCl}$ & 60 & 60 & 60 & 60 & 60 & 60 \\
\hline Kondagogu gum & 75 & 150 & 225 & -- & -- & -- \\
\hline Ghatti gum & -- & -- & -- & 75 & 150 & 225 \\
\hline PVP K-30 & 9 & 9 & 9 & 9 & 9 & 9 \\
\hline Magnesium Stearate & 6 & 6 & 6 & 6 & 6 & 6 \\
\hline Directly compressible lactose & 150 & 75 & -- & 150 & 75 & -- \\
\hline Total weight of tablet (mg) & 300 & 300 & 300 & 300 & 300 & 300 \\
\hline
\end{tabular}

\section{Coating of the prepared tablets}

For the primary coat, a solution of inulin $(10 \% \mathrm{w} / \mathrm{v})$ in hot water $(80$ $\left.{ }^{\circ} \mathrm{C}\right)$ was used to get the desired weight gain $(4 \% \mathrm{w} / \mathrm{w})$ on the tablets. Triethyl citrate $(1.5 \% \mathrm{w} / \mathrm{w}$ of inulin) and polyethylene glycol (PEG $6,000,4 \% \mathrm{w} / \mathrm{w}$ of inulin) were used as plasticizers and magnesium stearate $(12 \% \mathrm{w} / \mathrm{w}$ of inulin) was added to reduce the tackiness of the tablets. For the secondary coat, which is enteric in nature, a solution of shellac $(20 \% \mathrm{w} / \mathrm{v})$ in ethanol was used to get the desired weight gain $(2.5 \% \mathrm{w} / \mathrm{w})$ over the tablets. PEG $6000(4 \% \mathrm{w} / \mathrm{w}$ of shellac) was used as a plasticizer. Both the coating solutions were passed through a $0.3 \mathrm{~mm}$ sieve prior to coating. The prepared matrix tablets were coated with the inulin solution by spray coating. Coating of the tablets has been carried out in a conventional coating pan (Ram Scientific Suppliers, Bangalore, India) at an inlet temperature of $55^{\circ} \mathrm{C}$, pan rotation speed of $15 \mathrm{RPM}$, spray pressure of $4 \mathrm{~kg} / \mathrm{cm}^{2}$ and a spray rate of $10 \mathrm{ml} / \mathrm{min}$. A pilot type spray gun (Bullows 630) fitted with a $1 \mathrm{~mm}$ atomizing nozzle was used to spray the solution $[4,8,9]$. The coated tablets were subsequently evaluated for hardness and drug content.

\section{UV/Visible spectroscopy}

The wavelength of maximum absorbance $\left(\lambda_{\max }\right)$ of diltiazem hydrochloride drug was determined by scanning a known concentration of sample solution in the wavelength region $200-400 \mathrm{~nm}$ by using Shimadzu $1601 \mathrm{UV} /$ Visible spectrophotometer [24]. The $\lambda_{\max }$ was found to be $237 \mathrm{~nm}$ and this wavelength was used for further studies.

\section{FTIR Spectrophotometry}

In order to evaluate the integrity and compatibility of diltiazem with the carrier polymers in the polymer-drug matrix formulations, IR spectra of the drug and its optimized formulation were obtained by FTIR spectrophotometer (Perkin Elmer-1000, Japan), using a potassium bromide pellet method [25].

\section{Differential scanning calorimetry (DSC)}

DSC thermograms were recorded for pure diltiazem $\mathrm{HCl}$ drug and the optimized formulation. Accurately weighed samples were placed on aluminum plates, sealed with aluminum lids and heated at a constant rate of $5 \%$ min over a temperature range of $0-400{ }^{\circ} \mathrm{C}[15]$. All dynamic DSC studies were carried out using a DuPont thermal analyzer with 2010 DSC module.

\section{Scanning electron microscopy (SEM)}

To evaluate the uniformity of coat on the polymer-drug blend (core) tablet and to examine the coat morphology, scanning electron microscopy (Joel-LV-5600, USA) studies were performed [26].

\section{In vitro dissolution studies}

Dissolution testing of colon delivery systems with the conventional basket method has usually been conducted in different buffers for different periods of time to simulate the GI tract $\mathrm{pH}$ and transit time that the colon-specific delivery systems might encounter in vivo. Dissolution studies were carried out using USP XXII dissolution apparatus, basket type at $100 \mathrm{RPM}$ and $37 \pm 1{ }^{\circ} \mathrm{C}$. In vitro drug delivery studies were carried out for $2 \mathrm{~h}$ in $900 \mathrm{ml}$ of $1.2 \mathrm{pH}(\mathrm{HCl}$ buffer), $3 \mathrm{~h}$ in $900 \mathrm{ml}$ of $7.4 \mathrm{pH}$ (phosphate buffer) and for $6 \mathrm{~h}$ in 100 $\mathrm{ml}$ of SCF $[27,28]$. The samples were withdrawn at regular intervals and analysed spectrophotometrically at $237 \mathrm{~nm}$ for drug release.

\section{Preparation of simulated colonic fluid (SCF)}

To evaluate the performance of colon-specific delivery systems triggered by colon specific bacteria, animal cecal contents of rats have been utilized as an alternative dissolution medium. Because of the similarity of human and rodent colonic microflora, predominantly comprising Bifidobacteria, Bacteroides and Lactobacillus, rat cecal contents were used for dissolution studies. $4 \% \mathrm{w} / \mathrm{v}$ of rat cecal contents in $\mathrm{pH} 7$ saline phosphate buffer, incubated for $24 \mathrm{~h}$ was used as SCF [4, 29]. Incubation of the prepared solution was carried out in order to increase the enzyme concentration. This is done in order to simulate the conditions of human colon wherein a large amount of cecal contents would be present. As the bacteria present in cecal contents are predominantly anaerobic, all the processes were done by keeping the solution bubbled with carbon dioxide. Dissolution studies were carried out in both incubated and unincubated SCF to check the effect of the enzyme's action over drug release.

\section{Peppas model fitting}

Koresmeyer-Peppas model is one of the mathematical expression to evaluate the mechanism of drug delivery [30]. The KoresmeyerPeppas equation is as follows;

$$
\begin{array}{r}
\mathrm{Mt} / \mathrm{M} \infty=1-\mathrm{A}(\text { exp-kt) ....... (1) } \\
\log (1-\mathrm{Mt} / \mathrm{M} \infty)=\log \mathrm{A}-\mathrm{kt} / 2.303 \ldots \ldots .
\end{array}
$$

Where, $M_{t} / M_{\infty}$ is the fractional amount of drug released and $t$ is the time in h. In this study, the release constant, k and constant, A were calculated from the slopes and intercepts of the plot of In (1$M_{t} / M_{\infty}$ ) versus time $t$ respectively where, $M t$ is the amount of drug release at time $t ; M_{\infty}$ is the amount of drug release after infinite time; $\mathrm{k}$ is a release rate constant incorporating structural and geometric characteristics of the tablet, and $\mathrm{A}$ is the diffusional exponent indicative of the mechanism of drug release. 


\section{Stability studies}

Stability studies for the optimized formulation of matrix tablets was carried out to determine the effect of formulation additives on the stability of the drug in the final formulation and also to determine the physical stability. The optimized formulation was subjected to stability studies according to ICH guidelines by storing at $25 \pm 2{ }^{\circ} \mathrm{C} / 60 \pm 5 \% \mathrm{RH}$ and $30 \pm 2{ }^{\circ} \mathrm{C} / 65 \pm 5 \% \mathrm{RH}$ for 12 mo, and $40 \pm 2{ }^{\circ} \mathrm{C} / 75 \pm 5 \% \mathrm{RH}$ for 6 mo (Thermolab, Mumbai, India). The samples were analyzed and checked for changes in physical appearance and drug content at regular intervals [15, 17]

\section{RESULTS AND DISCUSSION}

The prepared core tablets were showing an average diameter of $9 \mathrm{~mm}$. Percentage weight variation, percent friability, and content of active ingredient for all the formulations were found to be well within United States Pharmacopoeia (USP) limits. The polymer coated tablets were evaluated for hardness and drug content. The prepared tablets were evaluated for properties such as hardness (Inweka hardness tester, Ahmedabad, India), thickness (Mitotoya screw gauge, Japan), weight variation (Shimadzu AW 120, Japan), percent friability (Electrolab EF-2 friabilator, Mumbai, India) and drug content (Shimadzu 1702 UV/Visible spectrophotometer, Japan). The data obtained for coated and uncoated tablets is given in table 2 .

Table 2: Evaluation data obtained for prepared tablets

\begin{tabular}{|c|c|c|c|c|c|c|c|}
\hline \multirow{2}{*}{$\begin{array}{l}\text { Formulation } \\
\text { code }\end{array}$} & \multicolumn{5}{|l|}{ Uncoated tablets } & \multicolumn{2}{|c|}{ Coated tablets } \\
\hline & $\begin{array}{l}\text { Weight variation* } \\
\text { (mg) }\end{array}$ & $\begin{array}{l}\text { Thickness* } \\
\text { (mm) }\end{array}$ & $\begin{array}{l}\text { Hardness* } \\
\left(\mathrm{kg} / \mathrm{cm}^{2}\right)\end{array}$ & $\begin{array}{l}\text { Friability* } \\
(\%)\end{array}$ & $\begin{array}{l}\text { \% Drug } \\
\text { content* }\end{array}$ & $\begin{array}{l}\text { Hardness* } \\
\left(\mathrm{kg} / \mathrm{cm}^{2}\right)\end{array}$ & $\begin{array}{l}\text { \% Drug } \\
\text { content }\end{array}$ \\
\hline KF1 & $301 \pm 3.2$ & $5.02 \pm 0.11$ & $5.7 \pm 0.52$ & $0.42 \pm 0.12$ & $100.2 \pm 2.4$ & $5.8 \pm 0.41$ & $99.8 \pm 1.8$ \\
\hline KF2 & $302 \pm 2.9$ & $5.01 \pm 0.10$ & $6.3 \pm 0.38$ & $0.38 \pm 0.11$ & $101.8 \pm 2.6$ & $6.5 \pm 0.51$ & $101.1 \pm 2.5$ \\
\hline KF3 & $299 \pm 3.1$ & $4.99 \pm 0.12$ & $6.6 \pm 0.45$ & $0.31 \pm 0.11$ & $100.3 \pm 3.1$ & $6.8 \pm 0.39$ & $99.5 \pm 2.3$ \\
\hline GF1 & $299 \pm 2.4$ & $5.01 \pm 0.11$ & $5.9 \pm 0.73$ & $0.39 \pm 0.13$ & $98.7 \pm 1.8$ & $6.2 \pm 0.46$ & $98.2 \pm 2.6$ \\
\hline GF2 & $301 \pm 3.1$ & $4.99 \pm 0.12$ & $6.9 \pm 0.82$ & $0.34 \pm 0.11$ & $100.5 \pm 2.2$ & $7.1 \pm 0.54$ & $99.7 \pm 1.4$ \\
\hline GF3 & $301 \pm 2.9$ & $4.98 \pm 0.13$ & $7.1 \pm 0.46$ & $0.28 \pm 0.12$ & $101.4 \pm 3.2$ & $7.4 \pm 0.84$ & $100.1 \pm 2.9$ \\
\hline
\end{tabular}

${ }^{*}$ mean $\pm \mathrm{SD}, \mathrm{n}=3$

From the table, it is clear that the hardness of the core tablets increased as the amount of polymer concentration in the tablet increased. Formulations containing $75 \% \mathrm{w} / \mathrm{w}$ of the gums (KF3 and GF3) showed the maximum hardness among the three ratios selected $(25 \%, 50 \%$ and $75 \%)$. Out of both the polymers, the tablets prepared with ghatti gum showed the maximum hardness of 7.1 $\mathrm{kg} / \mathrm{cm}^{2}$. The estimated drug content before and after the coating of the tablets is given in table 2 . From the table it was noticed that, the percentage of drug content lies in the range 98.7-101.4 and 98.2101.1 for before and after coating operation of the tablets respectively. This result clearly indicates that a slight reduction in drug content occurred during the coating operation and this is expected.

The FTIR spectra of pure diltiazem $\mathrm{HCl}$ and the formulation $\mathrm{KF} 3$ were found to be identical as shown in fig. 1. The characteristic IR absorption peaks of diltiazem at 2966 (aliphatic C-H stretch), 2837 $\left(\mathrm{O}-\mathrm{CH}_{3}\right.$ stretch), 2393 (amine $\mathrm{HCl}$ ), 1679 (lactam $\mathrm{C}=0$ stretch), 839 (o-substituted aromatic C-H out of plane deformation) and $781 \mathrm{~cm}^{-1}$ (p-substituted aromatic $\mathrm{C}-\mathrm{H}$ out of plane deformation) were obtained.

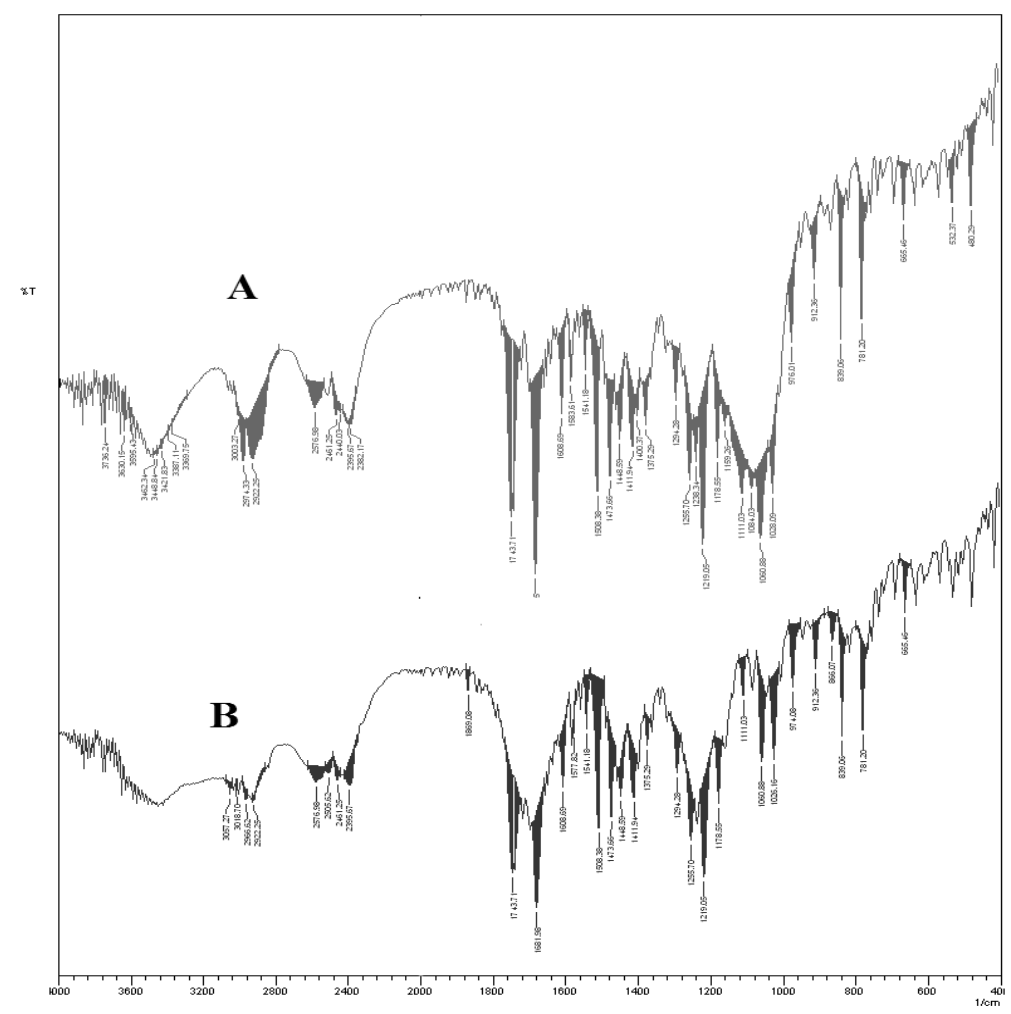

Fig. 1: FTIR chromatogram for pure diltiazem (peak A) and formulation KF3 (peak B) 
The FTIR spectra obtained indicated that no chemical interaction occurred between the drug, diltiazem, polymers and the excipients used in formulating the tablet. But, a slight shift in absorption peak position was noticed which indicated that physical interaction might have occurred between the drug and the polymer/excipients used.
From the DSC data obtained (fig. 2), it was evident that the melting point of diltiazem $\mathrm{HCl}$ has not changed after placing the tablets for stability studies (peaks at 217.16 and $218.34{ }^{\circ} \mathrm{C}$ for pure drug and formulation KF3 respectively). Hence, it may be inferred that there was no interaction between diltiazem and polymers used.

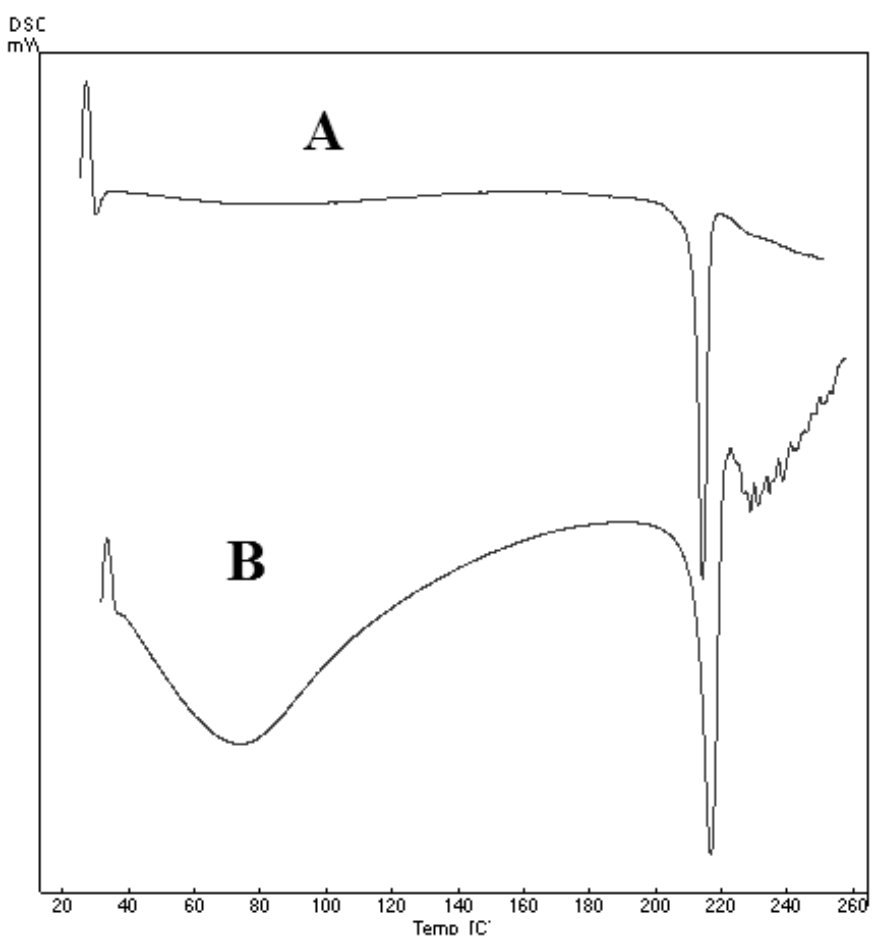

Fig. 2: DSC chromatogram for pure diltiazem $\mathrm{HCl}$ (peak A) and formulation KF3 (peak B)

From DSC results it can be concluded that the drug maintained its chemical identity throughout the process. The obtained SEM microphotographs of inulin and shellac coated tablets is shown in fig. 3.

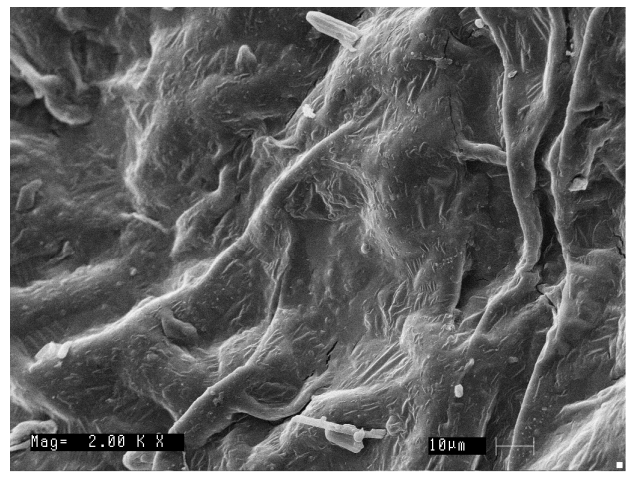

A

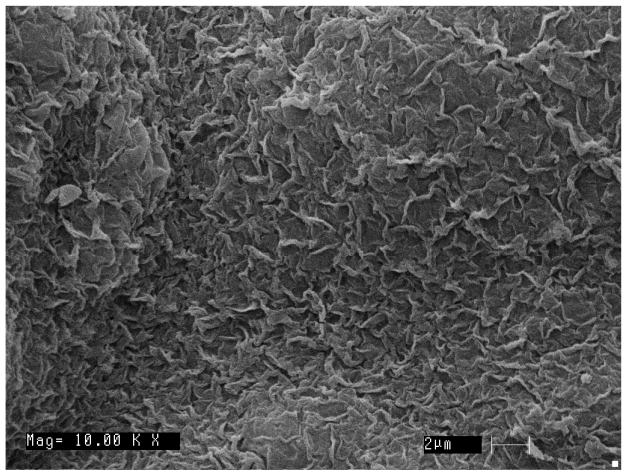

B

Fig. 3: SEM microphotograph of tablet surface after inulin (A) and shellac (B) coating

From the fig. it is evident that the shellac coating was smooth when compared to inulin coat. This can be attributed to the high molecular weight and complex structure of inulin.

The plot of cumulative drug release as a function of time is shown in fig. 4 and from the fig. it is clear that all the formulations did not show any drug release in $\mathrm{pH} 1.2$ buffer indicating that shellac has prevented the drug release in stomach environment. In vitro studies revealed that the formulations containing $25 \%$ of kondagogu gum and ghatti gum (KF1 and GF1 respectively) could not show sustained release whereas, the formulations $\mathrm{KF} 2$ and GF2 (50\% w/w of kondagogu gum and ghatti gum) showed sustained drug release from the coated tablets over a period of time. Kondagogu and ghatti gum formulations containing $25 \% \mathrm{w} / \mathrm{w}$ of the tablet (KF1 and GF1) released entire drug within $8 \mathrm{~h}$ of dissolution period. On the other hand, tablets containing $50 \% \mathrm{w} / \mathrm{w}$ of Kondagogu gum and ghatti gum (KF2 and GF2) showed about 47 and $51 \%$ of drug release at the end of $6 \mathrm{~h}$ indicating that the formulation did not with hold the drug before it reached the target site. 


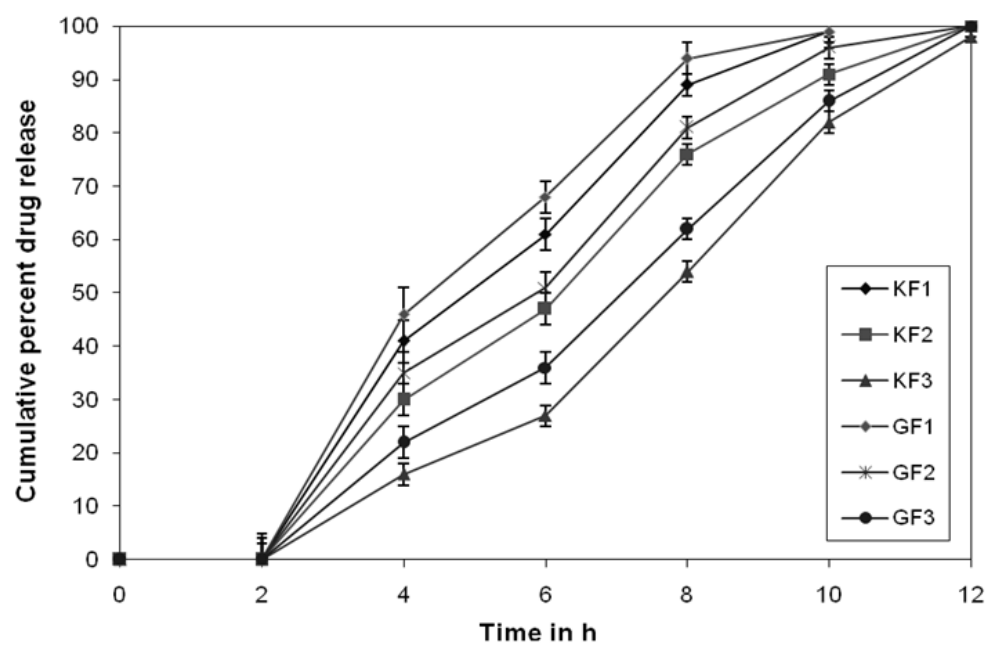

Fig. 4: In vitro drug release profile for the prepared tablet formulations (Data represents mean $\pm S E M(n=3)$

The formulations KF3 and GF3 were found to show a low amount of about 19 and $22 \%$ of the drug in $\mathrm{pH} 7.4$ phosphate buffer (small intestinal environment) and released the remaining amount of drug in the colonic environment. Drug delivery studies revealed that the tablets coated with shellac $(2.5 \% \mathrm{w} / \mathrm{w})$, prevented the drug release in stomach environment and inulin coated tablets $(4 \% \mathrm{w} / \mathrm{w})$ have limited the drug release in the small intestinal environment. On reaching the colonic environment, the inulin coat gets biodegraded in the bacteriological media and the drug present in the core gets exposed to the bacteriological solution. The bacteria present in the solution breakdown the polysaccharide units and the drug gets released.

At the end of $11 \mathrm{~h}$ of dissolution, $80 \%$ of the drug was released from the polymer-drug blend tablet. This is because of the multiplication of bacteria present in the cecal content, which got multiplied during the incubation period and the enzymes secreted by the bacteria have enhanced the rate of biodegradation of the coated and matrix polysaccharides used. Hence, for all the drug release studies incubated SCF was used.

The data obtained from in vitro drug release studies were fit into the Peppas model. From the plot of log Mt/Mø versus t, the parameters such as release constant (k), constant (A) and the regression coefficient $\left(\mathrm{R}^{2}\right)$ were calculated and the obtained values are shown in table 3.

In all the cases the value of A was found to be more than 2 . This result indicates that the release of drug from the polymer matrix formulations was found to be super case-II transport, i.e., drug release by a combination of both diffusion and erosion-controlled drug release. From the table it was concluded that formulation KF3 with $\mathrm{R}^{2}$ value of 0.9941 is the optimized formulation for colon targeted delivery.

The optimized formulation KF3 was subjected for stability studies. Stability studies of the drug formulations are performed to ascertain whether the drug undergoes any degradation during its shelf life. The data obtained from the stability studies are tabulated in table 4.

Table 3: Data obtained from Peppas model fitting for the formulations

\begin{tabular}{|c|c|c|c|c|c|c|}
\hline Parameters & KF1 & KF2 & KF3 & GF1 & GF2 & GF3 \\
\hline Constant (A) & 2.324 & 2.257 & 2.362 & 2.214 & 2.278 & 2.307 \\
\hline Regression coefficient $\left(\mathrm{R}^{2}\right)$ & 0.9867 & 0.9836 & 0.9941 & 0.9721 & 0.9875 & 0.9896 \\
\hline
\end{tabular}

Table 4: Stability study data of optimized formulation KF3

\begin{tabular}{llll}
\hline Stability condition & Sampling interval (Months) & Formulation KF3 \\
\cline { 3 - 3 } & & Physical appearance \\
\hline $25 \pm 2{ }^{\circ} \mathrm{C} /$ & 0 & No change & No change \\
$60 \pm 5 \% \mathrm{RH}$ & 3 & No change & $99.5 \pm 2.3$ \\
& 6 & No change & $99.2 \pm 2.8$ \\
$30 \pm 2{ }^{\circ} \mathrm{C} /$ & 12 & No change & $98.8 \pm 2.7$ \\
$65 \pm 5 \% \mathrm{RH}$ & 0 & No change & $99.5 \pm 2.6$ \\
& 3 & No change & $99.4 \pm 2.9$ \\
& 6 & No change & $98.9 \pm 2.6$ \\
$40 \pm 2{ }^{\circ} \mathrm{C} /$ & 12 & No change & $98.7 \pm 2.8$ \\
$75 \pm 5 \% \mathrm{RH}$ & 0 & No change & $99.5 \pm 2.4$ \\
& 3 & No change & $99.3 \pm 2.1$ \\
\hline
\end{tabular}

*Standard deviation $\mathrm{n}=3$, from the stability study data, it was clear that the drug was stable in the optimized formulation for the study period.

\section{CONCLUSION}

From the present study, it can be concluded that kondagogu gum and ghatti gum, which are natural and biodegradable polymers can be employed for use as carriers in developing colon targeted drug delivery systems. However, kondagogu gum was found to be superior to ghatti gum as a carrier for colon targeting.

\section{ACKNOWLEDGMENT}

The authors are thankful to Divis Laboratories, Hyderabad, India for providing gift sample of diltiazem $\mathrm{HCl}$ and Principal, MNR College of Pharmacy, Sangareddy, for encouragement and support in carrying out the work. 


\section{AUTHORS CONTRIBUTIONS}

All the author have contributed equally

\section{CONFLICT OF INTERESTS}

The authors have no conflict of interest to declare

\section{REFERENCES}

1. Amnon H, David S, Eran L, Sara E, Eytan K, Michael F. Pharmacokinetic and pharmacodynamic aspects of gastroretentive dosage forms. Int J Pharm 2004;277:141-53.

2. Abhishek B, Abhay SC. Argpyrimidine-tagged rutinencapsulated biocompatible (ethylene glycol dimers) nanoparticles: application for targeted drug delivery in experimental diabetes (Part 2). Int J Pharm 2017;528:8-17.

3. Seth A, Jack EB, Vivek SD. Colon-targeted oral drug delivery systems: design trends and approaches. AAPS PharmSciTech 2015;16:731-41.

4. Valluru Ravi, Siddaramaiah Hatna, Pramod Kumar TM. Influence of natural polymer coating on novel colon targeting drug delivery system. J Mat Sci: Mater Med 2008;19:2131-6.

5. Pallab Roy, Aliasgar Shahiwala. Multiparticulate formulation approach to pulsatile drug delivery: current perspectives. J Controlled Release 2009;134:74-80.

6. Hata T, Shimazaki Y, Kagayama A, Tamura S, Ueda S. Development of a novel drug delivery system, time-controlled explosion system (TES). Part 5 Animal pharmacodynamic and human bioavailability studies. Int J Pharm 1994;110:1-7.

7. Watanabe S, Kawai H, Katsuma M, Fukui M. Colon-specific drug release system. U. S. Patent, 09/183339; 1998.

8. Takemura S, Watanabe S, Katsuma M, Fukui M. Human gastrointestinal transit study of a novel colon delivery system (CODES) using scintigraphy. Proceedings of the International Symposium on Controlled Release Bioactive Material; 2000. p. 27.

9. Katsuma M, Watanabe S, Kawai H, Takemura S, Masuda Y, Fukui M. Studies on lactulose formulations for colon-specific drug delivery. Int J Pharm 2002;249:33-43.

10. Vinod VTP, Sashidhar R. Surface morphology, chemical and structural assignment of gum kondagogu (Cochlospermum gossypium D. C): an exudates tree gum of India. Indian J Nat Prod Resour 2010;1:181-92.

11. Janaki B, Sashidhar RB. Physico-chemical analysis of gum kondagogu (Cochlospermum gossypium): a potential food additive. Carbohydr Polym 2009;76:464-71.

12. Rathore HS, Sarubala M, Ramanathan G, Singaravelu S, Raja MD, Gupta S, et al. Fabrication of biomimetic porous novel sponge from gum kondagogu for wound dressing. Mater Lett 2016;177:108-11.

13. Vinod VTP, Sashidhar RB. Solution and conformational properties of gum kondagogu (Cochlospermum gossypium)-a natural product with immense potential as a food additive. Food Chem 2009;116:686-92.

14. Swati Malik, Ashok Kumar, Munish Ahuja. Synthesis of gum kondagogu-g-poly ( $N$-vinyl-2-pyrrolidone) and its evaluation as a mucoadhesive polymer. Int J Biol Macromol 2012;5:75662.
15. Valluru Ravi, Pramod Kumar TM. Investigation of kondagogu gum as a pharmaceutical excipient: a case study in developing a floating matrix tablet. Int J PharmTech Res 2013;5:70-8.

16. Ashok Kumar, Munish Ahuja. Carboxymethyl gum kondagoguchitosan polyelectrolyte complex nanoparticles: preparation and characterization. Int J Biolog Macromol 2013;62:80-4.

17. Vinod VTP, Sashidhar RB, Sarma VUM, Vijaya Saradhi UVR. Compositional analysis and rheological properties of gum kondagogu (Cochlospermum gossypium): a tree gum from India. J Agric Food Chem 2008;56:2199-207.

18. Gurpreet A, Malik K, Rana V, Singh I. Gum ghatti-a pharmaceutical excipient: development, evaluation and optimization of sustained release mucoadhesive matrix tablets of domperidone. Acta Pol Pharm 2012;69:725-37.

19. Valluru Ravi, Pramod Kumar TM, Siddaramaiah. Investigation of ghatti gum as a carrier to develop sustained release floating tablets of diltiazem hydrochloride. Thai J Pharm Sci 2012;36:155-64.

20. Cushman DR, Schick JW. Modified natural gums, U. S. Patent US 3891620; 1975.

21. Arvind KJ, Vishesh S, Meghali B, Rajesh V, Dhirendra SK. Electrosprayed inulin microparticles for microbiota triggered targeting of colon. Carbohydr Polym 2014;112:225-34.

22. Al-Gousous J, Penning $\mathrm{M}$, Langguth $\mathrm{P}$. Molecular insights into shellac film coats from different aqueous shellac salt solutions and effect on the disintegration of enteric-coated soft gelatin capsules. Int J Pharm 2015;484:283-91.

23. Jose S, Prema MT, Chacko AJ, Cinu TA, Souto EB. Colon-specific chitosan microspheres for chronotherapy of chronic stable angina. Colloids Surf B 2011;83:277-83.

24. Joao MM Leitao, Joaquim CG, Esteves da Silva Factorial analysis optimization of a Diltiazem kinetic spectrophotometric quantification method. Anal Chim Acta 2008;609:1-12.

25. Udaya ST, Tejraj MA. Modified guar gum matrix tablet for controlled release of diltiazem hydrochloride. J Controlled Release 2004;95:567-77.

26. Hee JP, Hyuck JJ, Myoung JH, Dae RL, Ha RC, Yong SC, et al. Colon-targeted delivery of solubilized bisacodyl by the doubly enteric-coated multiple-unit tablet. Eur J Pharm Sci 2017;102:172-9.

27. Rama Prasad YV, Krishnaiah YSR, Satyanarayana S. In vitro evaluation of guar gum as a carrier for colon-specific drug delivery. J Controlled Release 1998;51:281-7.

28. Hideyuki Tozaki, Junta Komoike, Chika Tada, Takako Maruyama, Akira Terabe, Sutomu Suzuki, et al. Chitosan capsules for colon-specific drug delivery: Improvement of insulin absorption from the rat colon. J Pharm Sci 1997;86:1016-21.

29. Sachin Kumar Singh, Ankit Kumar Yadav, Prudhviraj G, Monica Gulati, Puneet Kaur, Yogyata Vaidya. A novel dissolution method for evaluation of polysaccharide-based colon-specific delivery systems: a suitable alternative to animal sacrifice. Eur J Pharm Sci 2015;73L:72-80.

30. Peppas NA. Analysis of Fickian and non-fickian drug release from polymers. Pharm Acta Helvetiae 1985;60:110-1. 